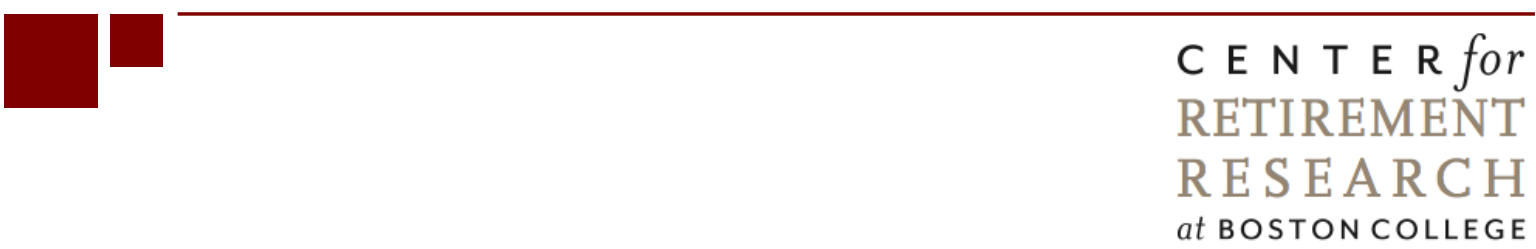

\title{
GUARDIANSHIP AND THE REPRESENTATIVE PAYEE PROGRAM
}

Anek Belbase and Geoffrey T. Sanzenbacher

CRR WP 2017-8

August 2017

\author{
Center for Retirement Research at Boston College \\ Hovey House \\ 140 Commonwealth Avenue \\ Chestnut Hill, MA 02467 \\ Tel: 617-552-1762 Fax: 617-552-0191 \\ http://crr.bc.edu
}

Both authors are with the Center for Retirement Research at Boston College. Anek Belbase is a research fellow and Geoffrey T. Sanzenbacher is a research economist. The research reported herein was performed pursuant to a grant from the U.S. Social Security Administration (SSA) funded as part of the Retirement Research Consortium. The opinions and conclusions expressed are solely those of the authors and do not represent the opinions or policy of SSA, any agency of the federal government, or Boston College. Neither the United States Government nor any agency thereof, nor any of their employees, makes any warranty, express or implied, or assumes any legal liability or responsibility for the accuracy, completeness, or usefulness of the contents of this report. Reference herein to any specific commercial product, process or service by trade name, trademark, manufacturer, or otherwise does not necessarily constitute or imply endorsement, recommendation or favoring by the United States Government or any agency thereof.

(C) 2017, Anek Belbase and Geoffrey T. Sanzenbacher. All rights reserved. Short sections of text, not to exceed two paragraphs, may be quoted without explicit permission provided that full credit, including (C) notice, is given to the source. 


\begin{abstract}
About the Center for Retirement Research
The Center for Retirement Research at Boston College, part of a consortium that includes parallel centers at the University of Michigan and the National Bureau of Economic Research, was established in 1998 through a grant from the Social Security Administration. The Center's mission is to produce first-class research and forge a strong link between the academic community and decision-makers in the public and private sectors around an issue of critical importance to the nation's future. To achieve this mission, the Center sponsors a wide variety of research projects, transmits new findings to a broad audience, trains new scholars, and broadens access to valuable data sources.
\end{abstract}

Center for Retirement Research at Boston College

Hovey House

140 Commonwealth Ave

Chestnut Hill, MA 02467

Tel: 617-552-1762 Fax: 617-552-0191

http://crr.bc.edu

Affiliated Institutions:

The Brookings Institution

Syracuse University

Urban Institute 


\begin{abstract}
Research suggests that 0.3 percent of all adults have been appointed a legal guardian. While the requirements for being placed into guardianship can vary from state to state, a lack of decision-making capacity is a precondition. As a result, one would expect Social Security beneficiaries who have a guardian to also have their guardian act as a representative payee. Yet little is known about the relationship between guardianship and the Representative Payee Program. In response to a request from the Social Security Administration, this report uses the Survey of Income and Program Participation (SIPP) linked to the Social Security Master Beneficiary File and the Supplemental Security Record to investigate three questions: 1) how many beneficiaries with representative payees have guardians?; 2) how many beneficiaries have their guardian as their payee?; and 3) what are the characteristics of those with both a payee and a guardian. Because the SIPP does not include individuals residing in nursing homes, the project also examines data from the Health and Retirement Study, which does include these individuals.
\end{abstract}

This paper found that:

- Guardianship is more common among those in the Representative Payee Program than in the population writ large, with between 5 percent to 11 percent of those with a representative payee also having a guardian, depending on the program and dataset considered.

- For those with both a representative payee and a guardian, the guardian serves as the payee the vast majority of the time.

- Individuals with a representative payee are more likely to have a guardian if they are older, white, and are not living with their representative payee.

The policy implications of this paper are:

- While guardianship could lessen the need for representative payees since it provides a protective legal arrangement, few individuals with a representative payee have one.

- As more representative payees are needed with the aging of the Baby Boomers, preexisting guardians seem unlikely to fill a large portion of the need. 


\section{Introduction}

Assigning an adult a guardian is a major intervention - in many ways it reduces the legal status of the person placed under guardianship to that of a minor. Because of the magnitude of the intervention, only a court can determine if an adult needs a guardian and subsequently assign them one. Perhaps for this reason, adult guardianship is relatively uncommon, with just 0.3 percent of all adults and 0.6 percent of adults ages 60 and over having one (Reynolds, 2002). ${ }^{1}$ Still, guardianship is likely much more common among those with a representative payee, since incapacity to manage one's finances is a pre-condition for both programs. To the extent the representative payee program needs to enlist more payees to meet the needs of the aging of the Baby Boomers (Anguelov, Ravida, and Weathers, 2015), guardians may be one obvious source. However, it is currently unclear how often individuals with representative payees have guardians and how often the guardian serves as the payee.

To better understand the interaction between guardianship and the Representative Payee Program, this report seeks to answer three questions: 1) how many beneficiaries with representative payees have guardians? 2) how many beneficiaries have their guardian as their payee? and 3) among those with a representative payee, who is most likely to have a guardian? ${ }^{2}$ To answer these questions, this report links the Survey of Income and Program Participation (SIPP) to Social Security’s Master Beneficiary Record (MBR) and Supplemental Security Record (SSR) to analyze the guardianship status of those with a representative payee. Because the SIPP does not include individuals residing in nursing homes, data from the Health and Retirement Study linked to Respondent Cross-Year Benefits data are also examined.

The results suggest that guardianship is more common amongst those with a payee than amongst those without one, but still uncommon. Depending on the dataset and program being considered, between 5 and 11 percent of beneficiaries with a representative payee have a guardian. In cases where a guardian is present, the guardian serves as the payee about 85 percent of the time. Guardianship is more common among whites, older individuals, and the more educated. Interestingly, guardianship is less common amongst those who reside with their

\footnotetext{
${ }^{1}$ Reynolds (2002) focuses on community-dwelling adults, which will also be the focus of the SIPP analysis discussed below.

${ }^{2}$ While it would be useful to understand what share of beneficiaries overall have a guardian (as opposed to only those with a payee), the data on guardianship status is collected on the representative payee form and so is only known for those with a payee.
} 
parents or children and those who live with their payee, indicating people may view pursuing guardianship as unnecessary when they are already serving as a Representative Payee and living with the beneficiary.

The report is organized as follows. The next section lays out the data used in this study. The following section provides estimates on the share of those with a representative payee who also have a guardian, descriptive statistics on those individuals' characteristics, and a regression analysis to analyze which beneficiaries with a payee are most likely to have a guardian. The report concludes by noting that even though guardianship is much more common amongst individuals with a representative payee than with those without one, it is unlikely to be a large source of payees in the future as more payees are enlisted to aid Baby Boomers.

\section{Data}

The data used in this report come from two public use datasets, the SIPP and the HRS, both linked to restricted Social Security administrative data.

\section{Survey of Income and Program Participation}

The SIPP is a series of national panels that has been run since 1984. In this report, panels following the 1996 SIPP redesign are used, encompassing the 1996, 2001, 2004, and 2008 panels. The overall sample is restricted to those who are 18 years of age or older. The SIPP features two basic questionnaires: 1) a core questionnaire that collects data on demographics, labor force participation, program participation, and income; and 2) topic-specific questionnaires that are asked once or twice per panel. Data from both questionnaires are used in this study. The core questionnaire is used to collect data on each individual's gender, age, marital status, education, race, ethnicity, employment status, and income. ${ }^{3}$ These variables will be used to examine the correlates of guardianship among those with a representative payee.

Data from two different topical modules are used in this study. The first is the topical module on household relationships, which is used to determine which family members an individual is living with at the time of their interview. ${ }^{4}$ This information will help determine if individuals with representative payees and guardians are more or less likely to live with their

\footnotetext{
${ }^{3}$ The analysis conducted is cross-sectional and so uses data from the core questionnaire of wave 1 of each panel. Data from two different topical modules is used in the study.

${ }^{4}$ This topical module was conducted in wave 2 for each of the panels used.
} 
families than those without guardians. The second is the module on physical and mental disabilities to determine how those conditions relate to the use of a guardian. ${ }^{5}$

Information on the use of a representative payee and on guardianship status come from one of two datasets, depending on the program being considered. For Social Security retirement and disability beneficiaries, data on payee and guardianship use come from the MBR. ${ }^{6}$ Beneficiaries were said to have a representative payee if the "Type of Payee" field was nonmissing and not equal to "Beneficiary Direct," which would indicate the individual is receiving their own benefit after a period of having a payee. This field was also used to identify whether the payee was a family member, with the "Custody Code" field providing information as to whether or not the beneficiary actually lived with the payee. Finally, the "Guardian Status" field was used to determine whether or not the individual with a payee had a guardian and whether or not that guardian also served as the payee. It is worth noting that because the guardian status field is derived from the representative payee form itself, it is not possible to identify individuals who have a guardian but not a payee.

For Supplemental Security Income (SSI), the analysis was based on the SSR. Beneficiaries were said to have a payee if the "Type of Payee" field was not missing and not equal to "Self," which would indicate a person was serving as their own payee after presumably having another person serve as their representative. This field was also used to determine whether the payee was a family member and whether the individual was living with their payee, with values of "Social Agency" or "Other" indicating the payee was not at the beneficiary's residence. ${ }^{7}$ Finally, the "Representative Payee Guardian/Competency Code” field clearly lays out whether the individual has a guardian and whether the guardian is also the payee.

\section{Health and Retirement Study}

While the SIPP is a useful survey for the purposes of this report, one limitation is that it focuses on the non-institutionalized population. To ensure that the share of beneficiaries with a payee and a guardian are not vastly different when these individuals are included, data on representative payee use and guardianship status were collected from the HRS linked to

\footnotetext{
${ }^{5}$ This topical module was conducted in wave 6 during the 2008 panel and wave 5 in the 1998, 2001, and 2004 panels.

${ }^{6}$ The linkage between the SIPP and the MBR and the SSR was conducted at SSA with the authors of this report providing code for the necessary tabulations.

${ }^{7}$ Individuals who lived at institutions serving as their payee were classified as living with their payee.
} 
restricted Respondent Cross-Year Benefits data derived from the MBR. Because these data are derived from the MBR, the assignment of representative payee and guardianship status are similar to that dataset. However, demographic information was not collected from the HRS for the purposes of this report because the sample size available with a representative payee is prohibitively small.

\section{Results}

This section presents results, first for the SIPP and then for the HRS.

\section{Survey of Income and Program Participation}

Merging the public use SIPP to the MBR and SSR, produced a sample of 37,778 retirement beneficiaries, 7,615 disability beneficiaries, and 4,763 SSI beneficiaries. To ensure consistency of the sample throughout the analysis, only individuals with a complete set of variables from the public-use SIPP were included in the analysis. ${ }^{8}$ Table 1 presents results for primary beneficiaries of OASI, SSDI, and SSI. The shares of recipients with a representative payee from the SIPP sample are similar to those reported in Anguelov, Ravida, and Weathers (2015), with the exception of the SSI program. About 2.1 percent of retirees in the SIPP sample had a payee, 10.0 percent of disability recipients, and 19.4 percent of SSI recipients, compared to 1.4, 10.7, and 29.9 percent respectively in Anguelov et al. The fact that fewer SSI recipients have a payee in the linked-SIPP data may stem from the fact that the SIPP sample does not include individuals in institutions, whereas the Anguelov et al. result is based on the universe of data. The Anguelov et al. result is also contemporaneous, whereas the analysis here uses data spanning a period of roughly 15 years.

Table 1 also shows that the majority of individuals with a payee do not have a guardian. In OASI, 10.3 percent of beneficiaries with a payee have a guardian compared to 5.4 percent and 5.0 percent for SSDI and SSI respectively. Although this suggests that guardianship is much more common among individuals with a representative payee than in the population at large (recall just 0.3 percent of adults have a guardian), it seems a small minority of individuals with a payee have a guardian. Still, it is worth noting that about 85 percent of the time a guardian has been appointed, that guardian is also the payee.

\footnotetext{
8 The results of this report were not qualitatively or quantitatively different when individuals who did not successfully merge to the public-use SIPP data were included.
} 
Figure 1 shows how guardianship amongst those with a representative payee evolves with age. Essentially, up until age 65 the share of individuals with a representative payee that also has a guardian is flat at around 5 to 6 percent. At age 65, the share jumps to 9 to 10 percent, mostly due to retirees (a similar jump is not observed in the SSI program). The figure also shows that at all ages when a guardian exists, that guardian also tends to be the payee. ${ }^{9}$

Table 2 illustrates differences in the characteristics of those with a representative payee by whether or not they also have a guardian. A few key patterns emerge. First, more educated individuals are also more likely to have a guardian - 37.5 percent of those with a guardian have at least some college compared to 28.5 percent for those without one. Beneficiaries with a guardian are also much more likely to be white compared to those without one, with rates of 74.5 percent and 59.2 percent respectively. Those with a severe mental disability are slightly more likely to have a guardian than those without one, but the difference is relatively small. Physical disability does not seem to be associated with guardianship use. Finally, people with a guardian are less likely to reside with their children or their parents, less likely to have a family member as a payee, and less likely to live with their representative payee. This pattern suggests that assigning guardianship may be a substitute for having someone living close by. Given that assigning guardianship is a complicated process involving the judicial system, it makes sense that when a representative payee or family member can be present in the home those people are less likely to go the extra step and assign a guardian. ${ }^{10}$ Indeed, a similar pattern was observed for the representative payee program itself - having family nearby appeared to serve as a substitute for that program as well (Belbase and Sanzenbacher, 2016).

Table 3 extends the more descriptive analysis presented in Table 2 by performing a simple probit regression and reporting the marginal effects of each variable on the probability of having a guardian. The direction of the coefficients is consistent with the results above, although some are insignificant. In the regression, being female, older, married, and Hispanic are all associated with a significantly lower likelihood of having a guardian amongst those with a representative payee. However, living with the representative payee is the most powerful

\footnotetext{
${ }^{9}$ Because the number of individuals with a guardian was too small in some cells, not all program/age combinations could be included in these tabs. For OASI, ages over 85 were excluded. For SSI, individuals 75 to 84 were excluded.

${ }^{10}$ A similar result was reported in Reynolds (2002) who found that having a smaller family network and not living with a spouse were associated with an increased likelihood of having a guardian.
} 
predictor of not having been assigned a guardian. Again, this suggests that when the representative payee is living with the beneficiary, they are less likely to go the next step and seek guardianship.

\section{Health and Retirement Study}

Table 4 presents the analog to Table 1 from the HRS. Unfortunately, the sample size of those with a representative payee in the HRS is relatively small - fewer than 300 observations compared to 2,700 in the SIPP - so analyses by program and by individual characteristics are not feasible. The results suggest that 5.2 percent of beneficiaries in the HRS with a representative payee also have a guardian. This result is significantly lower than the share found in the SIPP for retirement beneficiaries (which is the most relevant comparison), but is similar to the rates of guardianship for the SSDI and SSI programs. Qualitatively, like the SIPP, the HRS suggests that while guardianship seems much more common amongst those with a representative payee than those without one, the vast majority of adult beneficiaries with a payee do not have a guardian.

\section{Conclusion}

The number of individuals who need a representative payee is expected to grow through 2035, mostly due to simple demographics - the Baby Boom is aging. If many individuals with a representative payee also had a guardian then this fact could dent the need by offering a preexisting substitute. However, guardianship is uncommon even amongst those with a representative payee. Depending on the program and dataset being considered, 5 to 11 percent of those with a representative payee also have a guardian. It is unlikely guardianship can serve as a significant source of payees.

However, the descriptive and regression analyses suggest that for those with a representative payee, guardianship is serving as a substitute for other close family relationships. Those with a guardian were significantly less likely to be married and less likely to live with their payee. This finding suggests that even though guardianship may not serve as a substitute to a payee for the population at large, it may serve this purpose for those that could have more trouble finding a payee in the first place. 


\section{References}

Anguelov, Chris E., Gabriella Ravida, and Robert R. Weathers II. 2015. “Adult OASDI Beneficiaries and SSI Recipients Who Need Representative Payees: Projections for 2025 and 2035.” Social Security Bulletin 75(2): 1-17.

Belbase, Anek and Geoffrey T. Sanzenbacher. 2016. "Cognitive Impairment and Social Security’s Representative Payee Program.” Working Paper 2016-12. Chestnut Hill, MA: Center for Retirement Research at Boston College.

Reynolds, S.L. 2002. “Guardianship Primavera: A first Look at Factors Associated with Having a Legal Guardian using a Nationally Representative Sample of Community-Dwelling Adults.” Aging and Mental Health 6(2): 109-120. 
Figure 1. Share of Primary Beneficiaries with a Representative Payee who Have a Guardian

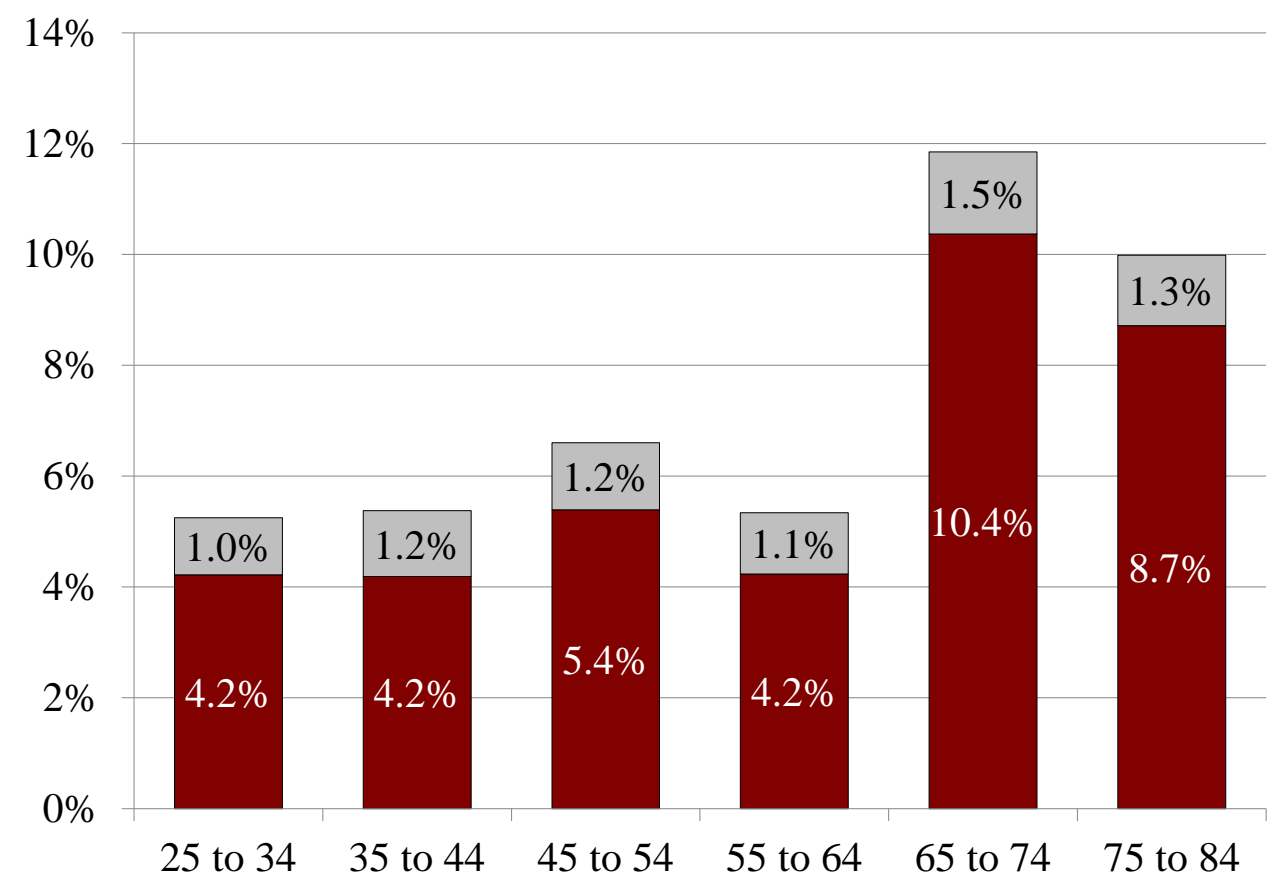

Source: Survey of Income and Program Participation (SIPP), 1996, 2001, 2004, and 2008 panels; Social Security Master Beneficiary Record (MBR); and Social Security Supplemental Security Record (SSR). 
Table 1. Share of Primary Beneficiaries with a Representative Payee and Guardian

\begin{tabular}{|c|c|c|c|c|c|}
\hline \multirow[b]{3}{*}{ Status } & \multirow[b]{3}{*}{ Obs. } & \multirow[b]{3}{*}{ Share } & \multicolumn{3}{|c|}{ Of those with a payee: } \\
\hline & & & \multirow[b]{2}{*}{$\begin{array}{l}\text { Share with } \\
\text { guardian }\end{array}$} & \multicolumn{2}{|c|}{ 95\% confidence int. } \\
\hline & & & & $\begin{array}{l}\text { Lower } \\
\text { bound }\end{array}$ & $\begin{array}{l}\text { Upper } \\
\text { bound }\end{array}$ \\
\hline Retirement & 37,778 & $100 \%$ & -- & -- & -- \\
\hline With payee & 786 & $2.1 \%$ & $100.0 \%$ & -- & -- \\
\hline With payee + guardian & 81 & $0.214 \%$ & $10.3 \%$ & $8.2 \%$ & $12.4 \%$ \\
\hline With guardian as payee & 69 & $0.183 \%$ & $8.8 \%$ & $6.8 \%$ & $10.8 \%$ \\
\hline Disability & 7,615 & $100 \%$ & -- & -- & -- \\
\hline With payee & 760 & $10.0 \%$ & $100 \%$ & -- & -- \\
\hline With payee + guardian & 41 & $0.5 \%$ & $5.4 \%$ & $3.8 \%$ & $7.0 \%$ \\
\hline With guardian as payee & 33 & $0.4 \%$ & $4.3 \%$ & $2.9 \%$ & $5.7 \%$ \\
\hline SSI & 4,763 & $100.0 \%$ & -- & -- & -- \\
\hline With payee & 922 & $19.4 \%$ & $100.0 \%$ & -- & -- \\
\hline With payee + guardian & 46 & $1.0 \%$ & $5.0 \%$ & $3.6 \%$ & $6.4 \%$ \\
\hline With guardian as payee & 35 & $0.7 \%$ & $3.8 \%$ & $2.6 \%$ & $5.0 \%$ \\
\hline
\end{tabular}

Source: Survey of Income and Program Participation (SIPP), 1996, 2001, 2004, and 2008 panels; Social Security Master Beneficiary Record (MBR); and Social Security Supplemental Security Record (SSR). 
Table 2. Select Characteristics of Primary Beneficiaries with a Representative Payee, by Guardianship Status

\begin{tabular}{lcc}
\hline & Has a guardian & Does not have guardian \\
\hline Demographics & $35.8 \%$ & \\
Female & 54.2 & $41.6 \%$ \\
Age & $23.0 \%$ & 48.2 \\
Married & $32.7 \%$ & $31.6 \%$ \\
High school dropout & $27.2 \%$ & $38.3 \%$ \\
Some college & $10.3 \%$ & $20.8 \%$ \\
College degree & $74.5 \%$ & $7.7 \%$ \\
White non-Hispanic & $14.5 \%$ & $59.2 \%$ \\
Black non-Hispanic & $4.2 \%$ & $24.6 \%$ \\
Hispanic & $6.7 \%$ & $10.6 \%$ \\
Other race/ethnicity & $67.9 \%$ & $5.8 \%$ \\
Reside in metro & & $72.6 \%$ \\
Employment/income & $30.3 \%$ & \\
Employed full month & $1.8 \%$ & $24.7 \%$ \\
Employed part month & $\$ 2,833$ & $3.0 \%$ \\
Monthly household income & & $\$ 2,722$ \\
Family & $15.8 \%$ & \\
Resides with parents & $17.6 \%$ & $22.8 \%$ \\
Resides with children & $53.3 \%$ & $25.4 \%$ \\
Family member payee & $70.3 \%$ & $75.9 \%$ \\
Live with payee & & $84.0 \%$ \\
Disability & $35.8 \%$ & \\
Severe mental disability & $36.4 \%$ & $30.7 \%$ \\
Severe physical disability & $9.1 \%$ & $36.8 \%$ \\
Blind/deaf/speech problems & & $8.4 \%$ \\
\hline
\end{tabular}

Source: SIPP, 1996, 2001, 2004, and 2008 panels; Social Security MBR; and Social Security SSR. 
Table 3. Marginal Effect of Selected Variables on Probability of Having a Guardian among Primary Beneficiaries with a Representative Payee

\begin{tabular}{lccc}
\hline Variable & Marginal effect & Standard error & P-value \\
\hline Female & $-2.30 \% * *$ & 0.010 & 0.016 \\
Age & $0.12 \% \%^{* *}$ & 0.000 & $<0.01$ \\
Married & $-3.52 \% * * *$ & 0.010 & 0.001 \\
High school drop out & $-1.03 \%$ & 0.012 & 0.373 \\
Some college & $1.49 \%$ & 0.011 & 0.191 \\
College degree & $0.66 \%$ & 0.016 & 0.678 \\
Black non-Hispanic & $-1.66 \%$ & 0.011 & 0.128 \\
Hispanic & $-4.04 \% * *$ & 0.020 & 0.044 \\
Other race & $1.05 \%$ & 0.017 & 0.544 \\
Resides in metro & $0.01 \%$ & 0.010 & 0.993 \\
Severe mental disability & $1.62 \%$ & 0.011 & 0.123 \\
Severe physical disability & $-1.60 \%$ & 0.011 & 0.129 \\
Blind/deaf/speech issue & $-1.29 \%$ & 0.018 & 0.486 \\
Income (in \$1,000s) & $-0.09 \%$ & 0.001 & 0.485 \\
Reside with parents & $-1.77 \%$ & 0.014 & 0.195 \\
Reside with children & $-0.23 \%$ & 0.011 & 0.837 \\
Reside with payee & $-3.75 \% * * *$ & 0.011 & 0.001 \\
SSDI recipient & $0.10 \%$ & 0.010 & 0.924 \\
SSI recipient & $-1.16 \%$ & 0.012 & 0.331 \\
\hline Observations & & 2,721 & \\
Psuedo R-squared & & 0.0805 & \\
\hline
\end{tabular}

Note: Standard errors on marginal effects are calculated using the delta method.

Source: SIPP, 1996, 2001, 2004, and 2008 panels; Social Security MBR; and Social Security SSR.

Table 4. Guardianship Status of HRS Beneficiaries with a Representative Payee

\begin{tabular}{lcccc}
\hline & & \multicolumn{2}{c}{$95 \%$ confidence int. } \\
\cline { 4 - 5 } & Observations & Share & Lower bound & Upper bound \\
\hline With payee & 291 & $100 \%$ & -- & -- \\
With guardian & 15 & $5.2 \%$ & $2.6 \%$ & $7.7 \%$ \\
With guardian as payee & 13 & $4.5 \%$ & $2.1 \%$ & $6.9 \%$ \\
\hline
\end{tabular}




\section{RECENT WORKING PAPERS FROM THE CENTER FOR RETIREMENT RESEARCH AT BOSTON COLLEGE}

The Relative Effects of Economic and Non-Economic Factors on Taxpayers' Preferences Between Front-Loaded and Back-Loaded Retirement Savings Plans Andrew D. Cuccia, Marcus M. Doxey, and Shane R. Stinson, July 2017

Social Security and Total Replacement Rates in Disability and Retirement Mashfiqur R. Khan, Matthew S. Rutledge, and Geoffrey T. Sanzenbacher, May 2017

An Experimental Analysis of Modifications to the Survivor Benefit Information within the Social Security Statement Jeffrey Diebold and Susan Camilleri, May 2017

Actuarial Inputs and the Valuation of Public Pension Liabilities and Contribution Requirements: A Simulation Approach

Gang Chen and David S. T. Matkin, May 2017

Why Are U.S. Households Claiming Social Security Later?

Wenliang Hou, Alicia H. Munnell, Geoffrey T. Sanzenbacher, and Yinji Li, April 2017

Rising Inequality in Life Expectancy by Socioeconomic Status Geoffrey T. Sanzenbacher, Anthony Webb, Candace M. Cosgrove, and Natalia S. Orlova, April 2017

The Effect of Job Mobility on Retirement Timing by Education Geoffrey T. Sanzenbacher, Steven A. Sass, and Christopher M. Gillis, February 2017

Would Reducing the Price of Employing an Older Worker Improve Labor Market Outcomes by Socioeconomic Status? Evidence from Health Insurance Premium Restrictions Matthew S. Rutledge and Caroline V. Crawford, December 2016

The Impact of Massachusetts Health Insurance Reform on Labor Mobility Norma B. Coe, Wenliang Hou, Alicia H. Munnell, Patrick J. Purcell, and Matthew S. Rutledge, December 2016

Work, Retirement, and Social Networks at Older Ages Eleonora Patacchini and Gary V. Engelhardt, November 2016

Calculating Expected Social Security Benefits by Race, Education, and Claiming Age Geoffrey T. Sanzenbacher and Jorge D. Ramos-Mercado, November 2016

All working papers are available on the Center for Retirement Research website (http://crr.bc.edu) and can be requested by e-mail (crr@bc.edu) or phone (617-552-1762). 